\title{
SELECTION AND MANAGEMENT OF ANAESTHESIA IN THOSE SUFFERING FROM DISEASES AND DISORDERS OF THE HEART
}

\author{
E M PAPPER, M D, F F A|r.CS $\nmid$
}

I FEEL very greatly moved and highly honoured to be given the privilege of deliverung the first Wesley Bourne lecture I did not have the privilege enjoyed by many of you, of being taught by Dr Wesley Bourne However, Wesley Bourne, in his writıngs as well as in his personal effort;, affected the entire world of anaesthesia

I met Dr Bourne for the first time in 1940 when I was a resident in anaesthesia at Bellevue Hospital in New York in Dr E A Rovenstine's department The charm and the interest that he displayed, not only to me but to all our people, was infectious beyond my descriptive ability. After this one meeting during my residency, I went into the U S army Wesley Bourne wrote to me at fairly regular intervals durnng the war and I am sure that he also wrote to many young men in the Anglo-American armed forces All these letters were written by hand and at some length The letters were newsy, full of what was going on in anaesthesia, and they had small amounts of very wonderful delicious and non-malicious gossip of the very best kind I chernshed those letters and read them avidly

I should now like to remind you of a few of the things that Wesley Bourne did and of a few facets of his life and work

He was born on April 24, 1886, in St Phillips, Barbados, the Britısh West Indies $\mathrm{He}$ was a distinguished alumnus of McGill University in the class of $1911 \mathrm{He}$ organized the Department of Anaesthesia and was its first professor He received many honours, among them the first Hickman medal of the Royal Society of Medicine of England in the early 1930's JHe was president of many societies, including the American Society of Anesthesiologists He published more than 100 scientific papers Although one can never weigh the quality of a man's accomplishment by the physical weight of his papers, in his case they were of uniformly high quality He collected many of these in a book which he called Mysterious Waters to Guard, which was published in $1955^{1}$ I think this book is important not only for the knowledge it contains and its delight but also because the selections are the ones he liked the most and put together in one collection If I had ever had the opportunity of makıng a collection of Wesley Bourne's papers, I would have put in others in addition to the ones he chose, because some of his omissions were truly landmarks in the development of our specialty Perhaps modesty or some other obscure reason resulted in these interesting omissions

-The First Wesley Bourne I ecture, McGill University, Montreal, P Q

TDepartment of Anesthesiology, Columbia University, College of Physicians and Surgeons, New York, N Y and Anesthesiology Service, The Presbyterian Hospital, New York, N Y

The author wishes to thank Dr Richard J Kitz for invaluable assistance in the preparation of this manuscript 
Among his major achievements are the lollowing He was among the very first to study the scientific basis of anaesthesia and to work with investigators in the basic fields His first scientufic paper on anaesthetic affaurs published in 1921 was on "Nitrous oxide analgesia and anaesthesia in obstetrics"2 When one reads of other aspects of his accomplishments at that time, it is obvious that there was opposition to his work and point of view among some of the clinicians of the penod, manly because he was so far in advance of his time and the scientific habit of thought in anaesthesia had not yet taken root I think Bourne's problem can be summarized by Machiavelli's words "There is nothing more difficult in its success than to take the lead in introduction in the new order of things." This was written over 400 years ago; it is still true today Wesley Bourne had this problem to overcome when he believed that there was a scientific basis to anaesthesia despite the opposition of powerfully placed practitioners

Wesley Bourne also communicated scientific knowledge to clinical practice in other forms $\mathrm{He}$ attended many meetings of anaesthesiologists $\mathrm{He}$ introduced the diploma course at McGlll (I believe that this was the first important organized clinical teaching effort for anaesthesia as a scientific discipline in the world)

He was among the first to predict the importance of enzymes to the understanding of the mechanism of anaesthetic action, which is almost sheer prophecy considering the way scientific research is now going

He was a great scholar in the classics and he quoted widely from them Almost all of his papers began with a quotation from non-medical writungs and they all ended with one The quotation came as a rule in the second or third paragraph at the beginning and it was in the penultinnate paragraph at the end of the paper He had a system in the way he did this and I hope he would be pleased at my venturing for a moment into classical literature, with a poem of Hilomer which $\mathbb{I}$ think describes him very well 4

That when he speaks what elocution flows
Soft as the fleeces of descending snows
The copious accent falls with easy art
Melting may fall and sink mito the heart

I am very sorry that he is not here toright but I hope this collective tribute to his greatness through my poor words will reach him and bring him cheer

I should like to move on fiom these brief words, madequate as they are, in honour of Wesley Bourne, to the subject of the lecture this evening, which is "The Selection and Management of Anaesthesia in Those Patients Suffering from Diseases and Disorders of the Heart"

I should like to start with a few of the historical aspects of the subject because I think the anaesthesiologist often loses sight of how he reached where he is in the clinical management of patients unless he takes historical perspective into account

There are majol developments which we must bear in mind that made both cardiac surgery and operations on patients with heart disease possible and ultimately safer These major developments are not exclusively anaesthetic nor are they enturely surgical Unsung among the important landmarks is the development of the blood bank and the development of substitutes for blood Secondly, 
chemotherapeutic agents are most important in this whole development It is quite appropriate to say that without antibiotics, without anticoagulants, and without intravenous fluids, operations on patients with heart disease would be impossible The third development is the perfection of extracorporeal perfusion devices and techniques These are physiological and they have been adapted to patients' needs by surgeons, physicians, and anaesthesiologists The fourth development in modern anaesthesia is a better understanding of anaesthetic problems

I should like, with this backgiound, to proceed to those factors which influence the clinician in anaesthesiology in the selection of patients and drugs for operations The most important quesion to ask at first is how to evaluate the risk in a patient with cardio-circulatory disease This is a very basic question, which is incompletely answerable at the present time except in terms of statistics These are useful but not definitive or final

One can ask the most skilful cardıologist about the 1 isk for anaesthesia and operation in terms of the function of the diseased heart In any given patient he is haid pressed to give you quantitative answers to your questions and what he often does is to say that the patient should not become anoxic or hypotensive This kind of answer is useless to the anaesthesiologist, because the twin sins of anoxia and hypotension are avoided for all patients The problem of induced hypotension is another matter entirely

Etsten and Proger in Boston provided one kind of answer when they stated that patients with hypertensive heait disease, valvular heart disease, or non-regurgitative heart disease who are not in congestive farlure present little greater operative risk than patients without such abnormalities ${ }^{5}$ The presence of coronary heart disease greatly increases the surgical risk In effect, what they said is that heart disease is not a termble danger if there is no fallure and if the coronary vessels are not involved

I think we can use this statement as a point of departure to look at this question of risk When one examines the question further, one has to examine why there may be no risk under certain circumstances

What are the factors that contribute to safety of the patient with heart disease during anaesthesia and operation? In short, why do patients with cardio-circulatory disease often do surprisingly well? In the first place the heart, even though it may be duseased, is really inherently a rugged organ ${ }^{6}$ Years ago Kountz studied hearts taken from patients who had been dead from 30 minutes to 6 hours and he was able to restore rhythmic contractions in 70 per cent of these hearts ${ }^{7}$ If one extends the period, the recovery rate of rhythmic contractions is dimmished, but it is amazing to think that one-half hour after death (maybe not all of us will be this rugged) 70 per cent of hearts will beat when they are simply put in an environment that is conducive to tissue life Corday, some years later, ligated both coronary arteries in the dog and demonstrated that the heart was able to maintain a functionally adequate curculation for several hours with only 15 per cent of the myocardium contracting This is remarkable evidence of ruggedness 8

Clinical anaesthetic experiences also show how rugged the heart can be The data that I am about to quote to you are taken out of context (and perhaps 
therefore unfaurly so) but in the paper reported from the University of Pennsylvania, there were approximately 16,000 patients who were in physical status one -that is, had no major systemic diseases-and there were no deaths attributable to anaesthesia in this whole group ${ }^{\circ}$ We can say that the heart must be inherently rugged to withstand the kunds of things that we do to it in our manipulations

At Pennsylvania in those patients who were considered monbund-including those from heart disease-the mortality rate from anaesthesia was only 10 per cent This figure appears high but it is still quite low when one considers the fact that the anaesthesiologist believed that the patients might die during or shortly after operation

The next favourable element, in addition to the rugged heart, is the skall of the anaesthesiologist Here I should like to take vigorous exception to the way in which the idea of skill has been misiepresented It is axiomatic, obviously, to anybody, that the anaesthesiologist who is better educated, better trained, and more competent can do a better job in the anaesthetic care of the sick than somebody who is not so well educated. But this cannot be the whole story because it has been distorted to say that the anaesthesiologist should use that agent or method or methods with which he is most familiar I like to look at this problem the other way around The anaesthesiologist who has only one or a few skalls ought not to be involved in the anaesthetic care of sick people with heart disease He ought to partıcipate only where his limited skalls will do no harm. To make the point, I like to think of this analogy If we say, "Let the anaesthesiologist do what he knows best," we might also say, "Let the surgeon do that operation that he does best and hope that the patients will have a complaunt that fits his particular skill and the operation that he can do"

The question of the anaesthesiologist's skill involves a thorough knowledge of the pharmacological properties of the anaesthetic and ancillary drugs and the physiological derangements that they produce, if he is to use them safely and effectively If this is considered to be the meaning of the "skill" of the anaesthesiologist I shall accept the modification gladly

Now let us look at the other side of the com What may make the heart of a patient such that anaesthesia would be dangerous? We turn from optumism to pessimism Is a patient who has coronary heart disease a greater risk than one who has not? Oddly enough, as one reviews the literature, there 1sn't enough information to provide a clear answer Among the published statistical data are following

Claude Beck in Cleveland found that patients with coronary artery disease had a mortality rate of 6 per cent, but he ieported only 429 patients ${ }^{10}$ Hannigan and his colleagues found a mortality rate of 52 per cent in patients with coronary artery disease in 58 cases, which is not of much significance when compared with a 34 per cent mortality rate in control cases who did not have coronary artery disease ${ }^{11}$ Baker and his colleagues report on 70 patients who had previous myocardial infarction and had 111 operative procedures with only 4 deaths ${ }^{12}$ Etsten and Proger, for non-cardiac operations on patients with coronary artery disease, reported a large series of 517 patients with coronary disease having a mortality rate of 29 per cent In 4154 patients anaesthetzzed and operated upon 
in the same time period who did not have coronary disease but who did have other torms of heart disease, the mortality rate was 20 per cent ${ }^{5}$ In their cases, then, the presence of coronary disease increased the mortality rate 50 per cent over the mortality rate of patients with heart disease but without coronary involvement

We had the opportunity to compare the results for series of patients in several institutions who had re-operations after cardiac resuscitation One group had been treated with open thoracotomy and one group with closed cardiac resuscitation The vulnerability to morbidity and mortality was considerably greater in the patients who had re-operations after open thoracotomy than after closed cardiac resuscitation ${ }^{13}$

Skınner and Pearce in 1964 reported 850 operations in cardiac patients over a 6 -year period ${ }^{14}$ These patients were very well studied and very well controlled They found that the more extensive the surgical procedure the more important was the cardiac status in determining the outcome For example, there were no deaths in patients with ingumal hernia among either cardiac or non-cardiac patients In bowel resection there was a 30 per cent mortality rate in patients with heart disease and 15 per cent in non-cardiacs, it the mortality rate for cardiac cases was twice as great as for non-cardiac cases in major procedures Transurethral resection of the prostate is a safe operation in their hands for patients with heart disease The duration of the operation afparently has nothing to do with the mortality rate when comparng cardiac with non-cardiac patients in any single operative group Regarding the anaesthetic agents, the authors drew no conclusion

The next point to mention about risk is that it has been well demonstrated that patients with myocardial infarction of less than three months' duration have an increased mortality rate compared with those in whom the infarction is older than three months In the Skinner-Pearce report the mortality rate was 40 per cent in the less-than-three-months group and 14 per cent in the greater-thanthree-months group If a patient has a healed myocardial infarction of more than three months' duration, if he has no signs or symptoms of congestive fallure, if his electrocardiogram is stable and back to what it was before the infarction, and if he has no anginal syndrome, he is for practical purposes essentially normal risk for anaesthesia and operation

I should like to go on now to a consideration of the preparation of the patient with heart disease for an anaesthetic and operation

In my opinion the anaesthesiologist is obligated to take a special history of his own, in addition to relying on that of the internist and the cardiologist, because people differ as to what they consider signs and symptoms of diminished cardiac reserve For instance, one of my colleagues who is a great athlete thinks that anybody who cannot climb eight flight of steps quickly has diminished cardiac reserve This is an obvious extreme Another of my colleagues thinks that anyone who drinks any alcohol is an alcoholic I thrik that the anaesthesiologist should take his own history about the elements that he wishes to look at and make a comparison with his colleague's history If there is some difference, then there should be a conference between the two to explain the differences 
The electrocardiogram is now taken on all patients with heart disease From the anaesthesiologist's point of view it has relatively little use as a datum in itself but it has great use when combined with the clinical story and it has interesting use as a base line for the conduct of anaesthesia and the study of anhythmias during anaesthesia

Now a word about electrolytes Most patients with heart disease and a history of congestive fallure not only are digitalized but many of them take diuretics preoperatively in order to get them into the best possible condition Durng diuresis, water and salts may be excreted in large amounts and some patients who are given rigorous diuretic therapy will be deficient in sodium or potassium or have hypovolaemia These electrolyte and water deficiencies should be checked on all patients with heart disease and should be corrected preoperatively if they are found to be out of order

There are those who believe that the administration of stored blood in rapid transfusion may provide a hyperkalaenic load that is dangerous for patients with heart disease The combined effects of digilalis, electrolyte imbalance, and anaesthetic agents are so interrelated that severe hypotension may be precipitated during and after induction of general anaesthesia, with or without the need for massive transfusion

I should like to make a comment about patients with cardiac decompensation or failure from the standpoint of digitalization Everybody is agreed that if a patient is in congestive fallure he should be digitalized preoperatively If he is not in fallure, then what ${ }^{2}$ This is where the difference of opmion in the argument comes in What I propose to do is to summarize the evidence upon which these conflicting opinions rest Ferrer, Harvey, and their colleagues at Columbia showed in the normal human heart that digitalization decreases the cardiac output ${ }^{15}$ People who read this paper inferred from this finding that it was dangerous to give digitalis to patients with normal hearts, or to patients with diseased hearts who were not in fallure Braunwald and colleagues ${ }^{16}$ found that digital1zation does in fact augment the contractile force of the non-falling human heart and constricts the systemic vascular bed so that the blood pressure remanns stable Cotton and Stopp observed that when the left atrial pressure was held constant, digitalis resulted in an elevation of cardiac output in the non-failing heart of the $\operatorname{dog}^{17}$ On the other hand, excessive digitalization may cause heart block and cardiac arrest, and under-digitalization may lead to tachycardia and heart fallure in these people It seems to me, therefore, that unless one can clearly show that a certain operation, or a certain anaesthetic, or a certain combined procedure, will inevitably lead to congestive fallure, then one is not justified in using digitalıs as a routme protective measure against future stress And buttressing this point of view is the fact that if you turn out to be incorrect in your estimate (and this does happen to those who do not wish to digitalize everybody with heart disease who is going to have a major operation), it is possible to digitalize a patient with lanatocide $C_{\text {i }}$ or comparable compounds very rapidly For a certain number of patients where the outcome is in doubt, the wiser clinical procedure would be to withhold digitalization until its need becomes evident For those patients of whom you feel convinced from your own expenence 
that they will always go into failure, preoperative digitalization is indicated It is not always possible to judge which ones are going to suffer faulure and which ones are not

I should now like to present my views about pre-anaesthetic medication in cardrac patients Pre-anaesthetic medication is part of the total preoperative evaluation, examination, and visit, and is the beginning of unaesthesia. So it is a bridge between these two functions Some of my colleagues speak about makng premedication rounds I think that the emphasis is not nght in this, and that the correct emphasis is that you are going to see a patient to evaluate and decide what to do in toto

If the patient with heart disease has no pain, warcotics should be omitted entrely or used in very small doses, because of the wrell-known effects of opiates upon the curculation, the respiration, the potential for nausea and vomiting, the potential for hypotension and for urmary difficulties If the patient does have pain, narcotics may be useful

A sensible view of premedication is to use a drug that will induce hypnosis, and almost all patients with heart disease have had experience with barbiturates or chloral hydrate or both I prefer simply to use as part of the premedication that drug and that dose which they have found satisfactory for their normal living at home

Scopolamine is preferred rather than atropine because of the psychic sedallive qualities which it possesses. There appears to be no threat of tachycardia after the usual piemedication doses

Many cardiac patients use hypotensive drugs We have studied Reserpine and aie abolutely convinced that there is no threat to hypertensive patients from the use of Reserpine ${ }^{18}$ As far as I am concerned, no patient need be taken off Reserpine because he is going to be anaesthetized or operated upon

As lar as tranquillizers are concerned, Equanil or'Miltown seems harmless in these patients

As to the anaesthetic management itself, provision /must be made for adequate ventilation and it might be that this is really the most important aspect of andesthetic care We have to provide analgesia and amnesia, we have to provide control for transfusions as you have already heard, and we have to avord postural change problems

Monitoning In view of our present ignorance the electrocardiograph should be used if there is an abnormal rhythm to begin with, or if an abnormal rhythm is highly likely to occur during the operation I see many people who look at the electrocardiogram, and I am one of them, really admuring the wave forms as they pass, without understanding too much about what they see I think if we are going to use these instruments to maximum effect, we should sit at the feet of competent electrocardiographers and learn something about their interpretation As for other measurements, II belleve that central venous pressure measurements done simultaneously with arterial pressure measurements are miost important In my opinion if you want to know more of the status of the patient's circulation, measurements of the arterial pressure and the central venous pressure aie a long step forward $\mathbb{I}$ would consider, however, a lalling arterial pressure 
and a rising venous pressure as one of the evidences not only of cardiac fallure but also of the possibility of over-transfiusion

I should like to confine my remarks about anaesthetic agents to a few general properties of the drugs and a few observations on basic principles of anaesthetic management

If one deprives an animal of his coinpensatory reflexes, then hypotension and diminished contractile force occur with all anaesthetics It came as quite a surprise to me to learn that nitrous oxade also did this and I think we have to accept the facts as they are The more rapid the development of anaesthesia and the deeper the anaesthesia, the more profound are the hypotensive effects on cardiac patients And I think that this is the basis for success for those who use nonpotent gases like nitrous oxide or ethylene for these cardiac patients It does not matter how you use them, you simply cannot use them too fast or too deep There is an automatic floor that is self-protective If one takes the time and the trouble to do this with the other anaesthetics you can do equally well

Regarding physiologic derangement', I wish to comment on a few points that were touched on earlier, mainly for emphasis

Continuous observational measurements of the electrocardiogram and artenal pressure show that intubation of patients with thiopental and succinylcholne alone will cause a very high incidence of abrupt hypotension and a very shortlived tachycardia $\mathbb{I}$ thmk this is not a good experience for patients with heart disease and I do believe that you can use the principles of this type of induction and intubation but modify them appropriately for most patients (and especially for the patient with heart disease) in a variety of ways You can follow the practice of Dr Gilbert of the Montreal Neurological Institute, by having a thorough surface or topical anaesthesia which prevents this type of response from occurring You can anaesthetize these patients lightly before giving them succinylcholine and intubating them, and this can even be done with non-potent gases like nitrous oxide or ethylene The prevention of "bucking" on the tube does not prevent the circulatory responses

I shall not spend any time in commentung on the specufic properties of the anaesthetic agents because these have been described very thoi oughly elsewhere However, I should like to make one or two comments about the arrhythmia problem in patients with heart disease

There is a very interesting clinical experience which $\mathbb{I}$ cannot explain, i $e$ that some arrhythmias which exist before anaesthesia actually improve when patients are anaesthetized There are many problems about arrhythmias and then treatment One should have a sensible attitude towards the common arrhythmias that occur during anaesthesia Many of them ase, as a matter of fact, reversed simply by lightening the anaesthesıa A good many of them will be cured by correcting anoxia and hypercapnia Sometimes asking the surgeon to stop what he is doing will halt the arrhythmia Sometimes increasing the blood volume, if it is deficient, will help Sometimes reducing the blood volume if it is over-sufficient will help Changing the body temperature towards normal will sometimes help In short, I think of arrhythmia correction as being designed towards a purpose If the patient's cardiovascular function is minterfered with by the arrhythmia, I think 
it should be corrected but, otherwise, one is well advised to leave well enough alone

Where does this leave us with the chorce of anaesthetic agents and methods? I think the anaesthesiologist, as Wesley Bourne would certainly say, cannot make a routine choice of anaesthesia for these patients He must evaluate all the clinical and scientific data and, with his knowledge of the action of drugs and their derangements, make his decision $\mathbb{I}$ think more often than not in these days of major operations, he will decide for general anaesthesia and he will decide for light general anaesthesıa with relaxants, employing as impeccable respiration as he can arrange This doesn't mean that this method is useful for all cases but it is a useful frame of reference Many patients are well served with regional anaesthesia, especially the ones whose operations will be adequately cared for If anaesthetization can be kept below level one to two, e g, in rectal surgery and lower extremity surgery Upper extremity surgery is an exception to what I have said, brachial block is very useful here

In the future, I think the anaesthesiologist has to prepare himself for the time when the patient with an acute myocardial infarction may be declared an emergency procedure in the same way as someone with acute appendicitis, and that an emergency operation, either repair of the coronary vessel, repair of the ventricle, or the total substitution of the heart, will be possible These are not imaginative speculations I think we would do service to our patients as well as improve our status with our colleagues in medicine if we were to improve our understanding of the problems which might arise

I should like, in conclusion, to tell you once again how very grateful I am to you and how deeply honoured I am to have had this privilege of giving the first Wesley Bourne lecture I hope that to some small extent, at least, I emulated the principles that he felt were important in providing you with some fundamental knowledge which is applicable to the care of sick people I obviously cannot emulate his erudition as a scholar of the classics but I almost feel that my inability to do so is good Its absence from this piesentation is further evidence of great affection and great respect for him in that $\mathbb{I}$ do not desure to intrude into an as ea and a way of lecture that is uniquely that of Wesley Bourne

\section{REFERENCES}

l Bourne, W Mystenous Waters to Guard Oxford Blackwell Scientific Pubhcations (1955)

2 Bounne, W \& Duncan, J W Nitrous Oxide Analgesia and Anesthesia in Obstetrics Canad M A J, 11818 (1921)

3 Machiavelli, N The Prince

4 Homer, Collected Poems

5 Etsten, $\mathbb{B}$ E \& Procer, S Operative Risk in Patients with Coronary Heart Disease J A M A 159845 (1955)

6 Dripps, $\mathbb{R}$ D, Strong, M J, \& Price, $H$ L The Heart and General Anesthesia Modiern Concepts of Cardiovascular Disease, American Heart Association, 32805 (1963)

7 Kountz, W B Revival of Human Hearts Ann Internal Med 10330 (1936)

8 Conday, $E$, Spritzler, $R$, \& Prinzmetai, M Studies on Coronary Circulation, Remarkable Reserve Power of Heart Ann Internal Med 31 450 (1949)

9 DhIPps, $\mathbb{R}$ D, LAMONT, A, \& Eckenhofr, $J \mathbb{E}$ Role of Anesthesia in Surgical Mortality J A M A 178261 (1961) 
10 BecK, C S, Lcighninger, D S, Brofm|an, B L, \& Bond, J F Some New Concepts of Coronary Heart Disease J A M A. 1682110 (1958)

11 Hannigan, C A, Wroblewsia, F, Lewis, W H, \& LADue, J S Major Surgery in Patients with Healed Myocardial Infarction Am J Med Sc1 222628 (1951)

12 Baker, H W, Grismer, J T, \& Wise, R H Risk of Surgery in Patients with Myocardial Infarctions A M A Arch Surg 70739 (1955)

13 Hanks, E C \& PAPPER, E M Reoperation alter Resuscitation from Cardiac Arrest Surg, Gynec \& Obst 119977 (1964)

14 Sranner, J F \& Prarce, M L Surgical Risk in the Cardiac Patient J Chronic Dis 17 $57(1964)$

15 Ferrer, M I, Harvey, $R$ M, Cathcalit, R T, Webster, C A, Richards, D W, \& Cournand, A Some Effects of Digoxin upon the Heart and Circulation in Man Circulation 1161 (1950)

16 Braunwald, E, Bloodwell, $\mathbb{R}$; Gor dberg, L I, \& Morrow, $\mathbb{A}$ Studies on Digitalis IV Observations in Man on Effects of Digitalis Preparations on the Contractility of the Non-failing Heart and on Total Vascular Resistance J Clin Invest 4052 (1961)

17 Cotron, $M$ DEV \& STOPP, $P$ E Action of Digitalis on the Non-faling Heart of the Dog Am J Physiol 192114 (1958)

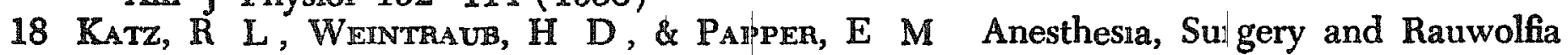
Anesthesiology 25142 (1964) 